\title{
CRISE DA POLÍTICA CONTEMPORÂNEA NO BRASIL: NOTAS DE UM DEBATE SOBRE O LULISMO ${ }^{1}$
}

\author{
Camila Massaro de Góes ${ }^{2}$ \\ Leonardo Octavio Belinelli de Brito ${ }^{3}$
}

\section{Resumo}

Buscamos refletir sobre o fenômeno controverso do "lulismo" - principalmente no que concerne as tensões presentes no capitalismo e na democracia ao longo dos Governos Lula - sob a ótica de dois dos principais autores que protagonizaram o debate em torno do tema, Francisco de Oliveira e André Singer. Tanto o sociólogo quanto o cientista político não fugiram ao desafio de interpretação do fenômeno, buscando integrar reflexões prévias a partir de diferentes ênfases e pontos de vista, as quais buscaremos lançar luz neste trabalho, na tentativa de entendê-los antes através da perspectiva de complementaridade do que a de oposição.

Palavras-chave: Lulismo, Francisco de Oliveira, André Singer, Política Contemporânea, Crise.

\begin{abstract}
We seek to reflect on the controversial phenomenon of "Lulism" - mainly in what concerns the existent tensions in capitalism and democracy over Lula Governments - from the perspective of two of the main authors who carried out the debate around the topic, Francisco de Oliveira and André Singer. Both the sociologist and the political scientist did not escape from the challenge of interpreting the phenomenon, seeking to integrate previous reflections from different emphases and perspectives, upon which wee seek to shed light on this work, in trying to understand them before through complementary perspective than opposition.
\end{abstract}

Keywords: Lulism, Francisco de Oliveira, André Singer, Contemporaneous Politics, Crisis.

\section{Resumen}

Reflexionamos sobre el fenómeno controvertido de lo "lulismo" - especialmente con respecto a las tensiones presentes en el capitalismo y la democracia en los gobiernos de Lula - desde la perspectiva de dos de los principales autores que protagonizaron el debate en torno al tema, Francisco de Oliveira y André Singer. Ambos el sociólogo y el politólogo no huyeron al desafío de interpretar el fenómeno, buscando integrar reflexiones anteriores de diferentes énfasis y perspectivas, en el que vamos a tratar de arrojar luz sobre este trabajo, para intentar los comprender ellos antes desde la perspectiva de complementariedad de que de oposición.

Palabras-clave: Lulismo, Francisco de Oliveira, André Singer, Política Contemporánea, Crisis.

\section{INTRODUÇÃO}

Como destaca Ruy Braga na apresentação do livro Hegemonia às avessas (2010), se lançar ao desafio de compreensão do fenômeno controverso da "hegemonia lulista" é um empreendimento de "grande monta", pois significa explorar "os fundamentos econômicos, políticos e culturais dessa forma sui generis de dominação social" num contexto "marcado pela crise econômica, pela guerra, pelo colapso ambiental e pela carência de exemplos políticos emuladores" no qual Lula alcançou "inéditos prestígio e admiração internacionais" (BRAGA, 2010, p.7). Se entendemos a originalidade e ineditismo do fenômeno como pressuposto

\footnotetext{
${ }^{1}$ DOI deste artigo: 10.5380/recp.v6i2.39043.

2 Mestre em Ciência Política (USP), E-mail: camilagoes2905@gmail.com

${ }^{3}$ Doutorando em Ciência Política (USP), belinelli.leonardo@gmail.com.
} 
consensual, por um lado, os sentidos do que significou o "lulismo", por outro, tampouco encontra unanimidade. Francisco de Oliveira e André Singer não fugiram ao desafio posto e protagonizaram o debate sobre a natureza deste fenômeno, buscando integrar suas reflexões prévias a partir de diferentes ênfases e pontos de vista, que buscaremos lançar luz neste artigo. Todavia, nossa tentativa de entendê-los será pautada pela ideia de que suas perspectivas podem ser vistas como complementares e não necessariamente opostas.

Os governos conduzidos pelo Partido dos Trabalhadores (PT) no Brasil têm sido analisados por diversos pensadores, de diferentes correntes e tradições. Neste artigo, longe de dar conta de toda a polêmica que o assunto contempla, buscaremos analisar principalmente o período dos governos Lula - embora a reflexão se estenda, evidentemente, ao contexto atual - assumindo como foco as tensões presentes no capitalismo e na democracia sob a ótica de dois dos principais interlocutores desta discussão, Oliveira e Singer. Como já dito, buscamos investigar a hipótese de que ambos os autores oferecem análises complementares partindo de pontos de vista distintos - enquanto Oliveira adota a perspectiva dos "de cima", Singer parte dos "de baixo". Embora a trajetória de ambos seja de amplo conhecimento, vale destacar algumas características fundamentais a fim de introduzirmos as questões que buscaremos trazer à tona.

Francisco de Oliveira, tal como André Singer, pode ser entendido como continuador do que se costuma chamar de "tradição crítica brasileira" (CF. ARANTES E ARANTES, 1997). Nesse sentido, seria um equívoco expor a análise que faz do período recente da história nacional, no qual o PT ocupou a presidência da República, sem indicar, ainda que sumariamente, como tal empreendimento intelectual se conecta tanto às teorizações anteriores do próprio autor como também às referências da tradição a qual dá prosseguimento. Uma boa síntese de suas preocupações e teses contemporâneas se encontra num texto feito por ocasião de homenagem à obra do crítico literário Roberto Schwarz. Neste relato, Oliveira (2007A, P.149) conta sobre a dívida intelectual que o seu ensaio de 2003, o Ornitorrinco (2013), tem com um dos ensaios mais importantes escritos por Schwarz ao longo dos anos 1990, intitulado Fim de século (1999).

Neste texto, o crítico literário enfatiza que a cultura tradicional às classes dominantes brasileiras, mesmo posta em situações novas, não desaparece, mas passa a fazer parte de um processo de outra natureza - essa mescla do tradicional e do moderno se prestou bem para um "emblema pitoresco da identidade nacional” (SCHWARZ, 1999, p.156). Fazendo uma análise do período neoliberal no Brasil, Schwarz afirma que essa mescla havia sofrido 
outra reviravolta, deixando "de funcionar como emblema nacional, para indicar um aspecto comum das industrializações retardatárias, passando a representar um traço característico da cena contemporânea tomada em seu conjunto” (ibid., p.157). Segundo Oliveira, o Brasilornitorrinco já se encontra aqui.

Este ensaio do autor de Ao vencedor as batatas foi transformado em programa de pesquisa, capitaneado por Oliveira, junto ao Centro de Estudos dos Direitos da Cidadania (CENEDIC) da USP, cuja liderança passaria a ser de Singer alguns anos depois. O projeto, chamado $O$ pensamento nas rupturas da politica, tinha como objetivo "reconhecer, no mesmo andamento, os pontos de negação-superação da ordem anterior ao neoliberalismo e a insuficiência dos paradigmas sociológicos para interpretá-los” (OLIVEIRA, 2007A, p.150). Num trocadilho usado por Oliveira, se trataria de estudar "um lugar fora das ideias, o Brasil desmanchado, e 'ideias fora de lugar', o neoliberalismo na periferia” (ibid., p.150). Grande parte dos seus textos, aqui analisados, foram produzidos em meio a esta pesquisa, que compreendeu o período de 2000 a 2005, além dos que foram produzidos depois, que apresentam conexão direta com o diagnóstico formulado neste momento anterior. Vale destacar que Singer não esteve presente nestes debates travados no CENEDIC, pois assumiu o cargo de porta-voz da presidência da república em 2003. Embora relativamente afastado deste ambiente acadêmico até 2006, destaca-se a proximidade com as decisões tomadas neste governo e o envolvimento direto com o que até então se imaginava um projeto para o país.

Um importante trabalho prévio do cientista político é Esquerda e Direita no Eleitorado Brasileiro, seu doutorado. Sempre preocupado com as motivações ideológicas do voto, Singer havia chegado a conclusão, a partir da análise das eleições presidenciais de 1989 e 1994, que o que diferenciava a esquerda e a direita no Brasil não era a busca pela igualdade - tratava-se de um eleitorado desejoso de mudanças igualitárias, mas que dividia-se ao longo de linhas ideológicas sobre como elas deveriam ser alcançadas:

\footnotetext{
Enquanto a esquerda parece estar associada à ideia de mobilização social e de contestação da autoridade repressiva do Estado, a direita, em oposição, parece estar associada à ideia de que mudanças só ocorrerão mediante um reforço da autoridade do Estado. O conservadorismo dos eleitores que se colocam à direita se expressa não em uma rejeição às mudanças, mas no apego à autoridade e à ordem (SINGER, 2002, p.164).
}

Nesse sentido, para o cientista político, as primeiras candidaturas Lula (1989 e 1994) representaram coerentemente este sistema de crenças afirmando a tese de que a mobilização social é o melhor caminho para atingir mais igualdade, "ainda que à custa de algum risco a 
ordem”. Muito diferente será sua visão dos Governos Lula e do fenômeno do lulismo, como veremos mais adiante, que se caracteriza justamente na afirmação da ordem.

Para Oliveira (2007A), os governos FHC e Lula promoveram um desmanche da "ordem getulista", o que acarretou uma profunda alteração nas relações sociais vigentes no país, para não falar da própria questão da acumulação de capital e do cálculo econômico. Ou seja, na situação atual, a sociedade passou a perder o controle sobre a determinação da exploração da força-de-trabalho, o que dificulta a sua contestação pela sociedade própria. A mundialização do capital, ao passo que retira a autonomia das decisões internas ao país, acaba também por abalar o poder das burguesias nacionais, que se torna um "simulacro". Para marcar a diferença com o período no qual vigoravam as esperanças desenvolvimentistas, ecoando a crítica de Schwarz, Oliveira afirma que "se o subdesenvolvimento era uma combinação em que o novo da acumulação de capital utilizava o velho como seu suporte [...] a nova situação caracteriza-se pelo oposto: as novas formas de acumulação de capital produzem o velho, mais que suportadas por ele" (OLIVEIRA, 2007A, p.151 - GRIFO DO AUTOR).

Para se ter uma ideia da gravidade da situação atual para Oliveira, o Ornitorrinco indica que as portas para a transformação social no Brasil estiveram abertas no período da Segunda Revolução Industrial. Daí a lembrança de Schwarz, acerca do comentário de Paulo Arantes, em debate sobre o ensaio, que observou que este raciocínio de Oliveira teria sido alimentado por "alguma saudade do subdesenvolvimento e de suas lutas, justificada em retrospecto pelo cerco atual” (SCHWARZ, 2012, p.154). Assim, seria um equívoco pensar o Brasil-ornitorrinco como subdesenvolvido, porque a inserção do país no processo de mundialização do capital alterou seu estatuto. Por outro lado, ele não consegue dar o salto para o novo regime de acumulação, pois lhe falta os meios necessários. Desta maneira, a inserção do país neste processo se deu pelo que lhe resta, que são as transferências de patrimônio (privatizações), prática que não é propriamente acumulação, nem reduz as desigualdades sociais (OLIVEIRA, 2013A, p.150). Na fórmula lapidar de Roberto Schwarz: “trata-se de um quadro de 'acumulação truncada' [...] em que o país se define pelo que não é; ou seja, pela condição subdesenvolvida, que não já não se aplica, e pelo modelo de acumulação, que não alcança” (SCHWARZ, 2012 , p.156).

De volta à universidade em 2006, nos anos subsequentes Singer se engajará no projeto de interpretação do "lulismo", publicando dois artigos importantes na revista Novos Estudos, nos quais analisa as trajetórias do PT e seu eleitorado - As Raízes sociais do Lulismo 
(2009) e A segunda alma do Partido dos Trabalhadores (2010) - Singer os reuniu, com outras reflexões, no discutido livro Sentidos do lulismo (2012), sua livre-docência. Logo na abertura do livro, inspirado no Marx de O Dezoito Brumário e nos estudos de Francisco Weffort sobre o populismo do período 1945-1964, ao fazer uma caracterização inicial do que chama de “lulismo", Singer interpreta o que considera como questão política central para o país:

O lulismo existe sob o signo da contradição. Conservação e mudança, reprodução e superação, decepção e esperança num mesmo movimento. É o caráter ambíguo do fenômeno que torna difícil a sua interpretação. No entanto, é preciso arriscar os sentidos, as resultantes das forças em jogo, se desejamos avançar na compreensão do período. Faço a minha aposta principal em forma de pergunta, pois o processo ainda está em curso: a inesperada trajetória do lulismo incidirá sobre contradições centrais do capitalismo brasileiro, abrindo caminho para colocá-las em patamar superior? (SINGER, 2012, p.9).

Diferente da análise de Oliveira, Singer indica que apenas "na aparência [...] o exmetalúrgico [Lula] manteve a ordem neoliberal estabelecida nos mandatos de Collor e FHC" (ibid., p.10 - GRIFO NOSSO). Para o autor, isso torna compreensível a desilusão exposta por Oliveira nas conclusões de seu O ornitorrinco, de 2003, embora afirme que depois de oito anos, o cenário teria se alterado e, portanto, seria preciso matizar tal interpretação. Se Singer concorda com Oliveira a respeito da mudança dos governos petistas em relação ao projeto original do partido (alma do Sion e espírito do Anhembi) - ou seja, em relação ao caráter "despolitizante" do lulismo - discorda, entretanto, de que se trate de um fenômeno regressivo, uma "hegemonia as avessas", interpretando-o mais como um projeto reformista fraco de construção de um Estado de bem-estar no Brasil. Nesse sentido, Singer enfatiza em seu argumento alguns dados positivos em relação aos governos Lula, como a queda dos juros, o aumento do superávit primário, os aumentos reais do salário mínimo e a expansão dos programas sociais e do crédito. Com isso, busca oferecer "um esquema interpretativo" a partir do qual seria possível refletir melhor sobre o "lulismo".

Entendemos que tanto Oliveira quanto Singer estão compartilhando um mesmo núcleo de preocupações em relação à realidade brasileira, mas que resultam em diagnósticos distintos, os quais procuraremos destrinchar nas próximas seções. Singer indica que o lulismo surge de um realinhamento eleitoral, o que significa dizer que as bases sociais de voto no PT foram alteradas. Em termos sintéticos, na eleição de 2002 o PT teria contado com votos de pessoas com renda mais alta do que em 2006. Já Oliveira defende a tese de que há a formação de uma nova classe social no país a partir "das recentes convergências programáticas entre o 
PT e o PSDB" e do "aparente paradoxo que o governo de Lula realiza o programa de FHC, radicalizando-o". O sociólogo observa que:

[...] não se trata de um equívoco, mas de uma verdadeira nova classe social, que se estrutura sobre, de um lado, técnicos e intelectuais doublés de banqueiros, núcleo duro do PSDB, e operários transformados em operadores de fundos de previdência, núcleo duro do PT. A identidade dos dois casos reside no controle do acesso aos fundos públicos, no conhecimento do "mapa da mina" (OLIVEIRA, 2013A, p.147).

Desta forma, poderíamos enunciar como a questão central, aqui destacada, da seguinte maneira: é como se Oliveira fizesse sua análise observando os movimentos sociais e políticos daqueles que dominam, enquanto Singer sublinhasse os efeitos e o papel do lulismo sobre os dominados. Dito isso, vale reafirmar que se existe tal diferença, é preciso indicar que tais perspectivas podem se complementar, a depender de como se observe.

\section{DO PONTO DE VISTA DOS DE CIMA: CONSERVAÇÃO-REPRODUÇÃO}

Frente ao quadro histórico-econômico desolador, o lugar da política contemporânea é considerado problemático para Oliveira. Para compreender a tensão política atual - interesse de fundo deste trabalho - é necessário entender antes: 1) qual é o estatuto da política nas condições brasileiras e nas articulações que estas têm com a situação global; e 2) como o sociólogo avalia esse cenário. A resposta ao primeiro ponto é encontrada no texto Política numa era da indeterminação (2007B). Neste texto, Oliveira questiona as possibilidades da "invenção política no Brasil” e como pensá-la. O ponto de partida desta reflexão é o conceito de política de Jacques Rancière. ${ }^{4}$ Assim como o filósofo francês, Oliveira distingue "política" de "polícia" (do termo francês police). Este último termo designa as "operações dos atores do campo inventado". Fazendo uma analogia, Oliveira indica que "política é quântica, enquanto a "polícia" é determinista" (OLIVEIRA, 2007B, p.16). Como observa Laymert Santos (2007) - em Brasil Contemporâneo: estado de exceção? - o recurso às

\footnotetext{
${ }^{4} \mathrm{Na}$ interpretação de Oliveira: "Política no sentido de Rancière é a reclamação da parte dos que não têm parte; e por isso se constitui em dissenso. Nessa acepção, os que fazem política distinguem-se por pautar os movimentos do outro, do adversário, por impor-lhe minimamente uma agenda de questões sobre as quais e e em torno dos quais se desenrola o conflito. Impor a agenda não significa necessariamente ter êxito, ganhar a disputa; antes, significa criar um campo específico dentro do qual o adversário é obrigado a se mover [...] Essa concepção abre as portas para sua permanente reinvenção, no sentido de que toda proposta, e sua resposta, que consiga sair do campo anteriormente demarcado cria um novo campo, que é, em si mesmo, uma nova qualidade dos atores políticos. Há, pois, na política, uma permanente mudança de qualidade. A força de uma invenção se expressa na capacidade de manter o adversário nos limites do campo criado pela proposta/resposta [...] Gramsci chamaria essa capacidade de hegemonia [...] produção conflitiva do consenso" (OLIVEIRA, 2007B, p.15).
} 
analogias das ciências naturais tem a função de dar conta das dimensões de previsibilidade e imprevisibilidade, bem como do consenso e do dissenso, na política.

É esta relação entre previsibilidade/imprevisibilidade que estruturará toda a percepção de Oliveira sobre a história recente do país, estruturada em três partes. $\mathrm{Na}$ primeira, o período compreendido entre 1964 e 1990 é visto como época de invenção política - tese que aparece também em O Ornitorrinco - ainda que limitada. Para o sociólogo, este foi um período de "internalização das decisões"; ou seja, um tempo no qual o "espaço nacional [foi pensado] como centro" (OLIVEIRA, 2007B, p.17). Já na década de 1990, teria ocorrido o fim deste período de invenção. Resumindo o argumento de Oliveira, afirma Santos:

Apoiado em Rancière, em Habermas e na analogia com as teorias da física, Chico lança um olhar retrospectivo para a história recente do Brasil e constata que as invenções políticas produzidas no período 1964-1990 não foram suficientemente poderosas para romper o quadro estreito da polícia e operar um salto qualitativo. Por outro lado, à luz do que aconteceu depois, fica evidente que a difícil e laboriosa construção do que parecia ser uma nova sociabilidade mais civilizada era inconsistente. Mais ainda: "a nova transparência" era falsa. Ora, é essa dolorosa revisão que não só precipita o pensamento na incerteza, como o leva a procurar novos parâmetros para analisar o campo de forças políticas na era da indeterminação (SANTOS, 2007, p.292).

A “era da indeterminação", por sua vez, é analisada na segunda parte do texto. $\mathrm{Na}$ política nacional, Collor é identificado como o divisor de águas. Este período foi inaugurado com a "financeirização do capital", paralelamente à "explosão da dívida externa” e da "perda de centralidade do trabalho” ocorrida devido à Terceira Revolução Industrial. Isso gerou, e continuou a criar, a própria imprevisibilidade da política. ${ }^{5}$ Daí os sinais de regressão apontados por Oliveira:

[...] em lugar de uma hegemonia burguesa que se alimentasse das "virtudes" cívicas do mercado, requer-se permanentemente coerção estatal, sem o que todo o edifício desaba [...] tanto aos olhos da sociedade quanto na prática do empresariado, a lei é a do vale-tudo. Na fórmula gramsciana de consenso mais coerção, a porção de coerção continua sendo a mais importante e por isso não há nenhuma possibilidade de "interesses bem compreendidos" tocquevillianos, e a

\footnotetext{
5 Para Oliveira: “Assim, em lugar de uma hegemonia burguesa que se alimentasse das "virtudes" cívicas do mercado, requer-se permanentemente coerção estatal, sem o que o todo o edifício desaba [...] tanto aos olhos da sociedade quanto na prática do empresariado, a lei é a do vale-tudo. $\mathrm{Na}$ fórmula gramsciana de consenso mais coerção, a porção de coerção continua sendo a mais importante e por isso não há nenhuma possibilidade de "interesses bem compreendidos" tocquevillianos, e a república não nasce da "virtude" do mercado. Uma espécie de "exceção permanente" schmittiana que anula as possibilidades de virtú da sociedade civil, entendida esta no sentido de blocos de interesses organizados que se demarcam entre si e com relação ao Estado. Um movimento browniano incessante de acomodações e reacomodações, de deslocamentos e deslizamentos, de pesados ajustes de contas, que ultrapassa os limites do consenso da "política policial" e não chega a formar outro campo de conflito, em que exatamente a operação de um novo consenso possa ser "política". Trata-se de uma "ação anticomuncativa". De uma falta de formas, sem as quais a política não se faz" (OLIVEIRA apud SANTOS, 2007, p.294).
} 
república não nasce da "virtude" do mercado. Uma espécie de "exceção permanente" schmittiana que anula as possibilidades de virtú da sociedade civil, entendida esta no sentido de blocos de interesses organizados que se demarcam entre si e com relação ao Estado (OLIVEIRA, 2007B, p.35-36).

Assim, o conceito schmittiano de "estado de exceção" aparece vinculado ao esvaziamento da política - combinando, então, gestão cotidiana e coerção renovada. O que interessa é que o central da teoria está aí indicando a falta de funcionamento da sociedade burguesa. O paradoxo maior é que a política é esvaziada no momento em que se ampliam a "participação da cidadania" e a representação democrática, tal como teria indicado as eleições de 2002. Esta situação nos impediria de compreender o que há de excepcional no "estado de exceção": "como se a opressão fosse tão forte, tão intensa, que acabávamos vivendo a desordem como se ela fosse a própria ordem, e a exceção como a normalidade” (SANTOS, 2007, p.295).

Em busca da avaliação de Oliveira acerca do que foi realizado neste processo de indeterminação política, nos voltamos para outros dois textos do autor: O momento Lênin (2007C) e Hegemonia às avessas (2010). No primeiro, ainda com a categoria “estado de exceção", o sociólogo tenta compreender o comportamento de Lula, na Presidência da República, por meio da uma comparação com Lênin no contexto que precedeu à Revolução Russa. Ambos os líderes teriam pregado a transformação da sociedade em que viviam e se viram, cada um em seu tempo, frente a uma situação de indeterminação.

Para Oliveira, a Rússia ilustrava um caso de subdesenvolvimento e de inserção no capitalismo de modo desigual e combinado. Dessa "desigualdade combinada" decorreriam tanto a "incapacidade revolucionária" da burguesia russa quanto a precocidade do movimento operário - "uma espécie de truncamento produzido pela sua inserção entre um capitalismo dinâmico e desapiedado, impulsionado de fora pelos imperialismos já referidos, e as pré-classes que a implantação do capitalismo criava velozmente na Rússia” (OLIVEIRA, 2007C, p.258).

Laymert Santos pontua que há aqui uma conexão profunda com O ornitorrinco; como se Oliveira nos quisesse fazer ver que a chance histórica que se abre de modo conjuntural em 1917 na Rússia seria da mesma natureza que aquela aberta mais tarde no continente latino-americano, e que foi longamente analisada, no caso brasileiro, nesse último texto: "um momento de indeterminação, um estado de exceção no qual, por uma série de razões, produziu-se ao mesmo tempo uma burguesia incapaz de fazer sua própria evolução e um proletariado precoce" (SANTOS, 2007, p.305-306). Vista desse ângulo, a situação russa 
propiciou duas alternativas: 1) conduzir o país no sentido de tentar desenvolvê-lo nos "termos do subdesenvolvimento capitalista" ou 2) fazer um experimento político, ousando "produzir formas de sociedades socialistas". Como se sabe, a segunda opção prevaleceu. Oliveira nos questiona, então, o que teria permitido isso.

A tradição marxista costuma atribuir a iniciativa às classes dominadas, quando da obtenção de vitória em insurreições revolucionárias. Embora concorde com a ênfase nos operários e camponeses-soldados, Oliveira destaca que, no caso soviético, estas não eram classes já constituídas, mas classes em devir. Nesse sentido, destaca três pontos: 1) no "momento Lênin", as classes revolucionárias não estão dadas, mas precisam de uma brecha para que realizem seu potencial; 2) a experimentação política pode dar numa revolução ou numa contrarrevolução, como indica a Alemanha do período e 3) no momento da indeterminação, é preciso tomar uma decisão política de risco e quem pode fazê-lo é o líder carismático. Aqui, a articulação central apontada por Oliveira se dá entre as noções de "estado de exceção", "soberania" e "carisma", que, no entanto, o autor não chega a desenvolver plenamente.

Caracterizado o momento russo, Oliveira se volta para o Brasil. A eleição de Lula teria sido uma "virtualidade" da "conjuntura de indeterminação" (OLIVEIRA, 2007B, p.261), criada pela financeirização do capital, pelo desmanche e outros fenômenos correlatos. Neste contexto, se deu a suspensão da relação entre economia e política, no sentido da relação entre classes e representação. Para Oliveira, "ao contrário de Lênin, que percebeu a falência do sistema de poder e a aprofundou ao dirigir o movimento para a revolução socialista, Lula recompôs o sistema político que o turbilhão combinado da desregulamentação de FHC e da globalização havia implodido" (ibid., p.266). E isso só foi possível, em grande parte, pelo carisma de Lula e seu partido, resultado do momento anterior, no qual eram vistos como os principais atores do "largo movimento de reinvenção da política" do período que vai do final da Ditadura à redemocratização. No entender de Oliveira:

\footnotetext{
O carisma de Lula se exerce, portanto, num sentido conservador e até mesmo contrarrevolucionário, atuando em duas frentes. Por um lado, face das demandas e das expectativas populares, seu efeito é o de um poderoso anestesiante que ao mesmo tempo paralisa as reivindicações e opera uma espécie de sequestro da sociedade organizadas, em suma, o carisma é despolitizante e, nesse sentido, é visto negativamente [...] (SANTOS, 2007, p.308-9).
}

Apesar das lideranças do PT terem reconstruído o sistema político e econômico que estava em crise, não se poderia afirmar que o período da exceção terminou. O processo 
de financeirização do capital instituiu uma nova relação Estado-mercado, que é levada a cabo por uma nova classe social, já analisada em O ornitorrinco. No entanto, vale ressaltar que essa classe não é detentora da soberania - é ela quem negocia com o capital financeiro, verdadeiro poderoso, os acessos aos fundos públicos. Por outro lado, Oliveira enfatiza a decomposição das classes trabalhadoras. Um dos traços destes processos é a sua exclusão da política, na medida em que o "lulismo-petismo" não permite que suas pautas e reivindicações tomem o centro do debate político, que é esvaziado sob a forma de um "populismo emergente" (OLIVEIRA, 2007C, p.285). Seria inadequado, portanto, falar em hegemonia, porque não há “direção moral da sociedade"; estaríamos, antes, "além da hegemonia".

Assim, Oliveira dá outro passo - a recomposição lulista, para ele, é só aparente. $\mathrm{Na}$ verdade, não há caminho de volta porque o momento de indeterminação, em vez de se “resolver", se prolonga com a transferência do exercício da soberania da esfera da política para a economia, instância que agora instrumentaliza o Estado, através da nova classe, para implementar suas decisões em regime de exceção permanente (SANTOS, 2007, p.310-311). Para Oliveira, o domínio da economia pela política é a contrarrevolução de nosso tempo. Como seu impacto principal, não há mais a (retórica da) universalização de direitos da cidadania - "o Estado mínimo da falsa utopia neoliberal não é mínimo da economia, como pregam os tolos; ele se faz mínimo é na política" (OLIVEIRA, 2007C, p.286).

Em Hegemonia às avessas a avaliação de Oliveira é um pouco diversa - há uma avaliação do governo de Lula segundo a qual este não seria populista, bem como há a adoção da ideia de hegemonia, antes descartada. Publicado originalmente na revista Piaú, em janeiro de 2007, o texto é marcado pela então recente vitória de Lula, reeleito sobre Geraldo Alckmin (PSDB). Nele, Oliveira ataca principalmente a ideia de que o PSDB só teria tido votos dos "ricos", enquanto o PT dos "pobres" (id., 2010A, p.21). Contra esta tese, o sociólogo procurar fornecer uma explicação para os movimentos eleitorais das classes sociais brasileiras.

Oliveira destaca que um dos resultados das eleições de 2006, nos seus diversos níveis, foi a grande mistura caótica das siglas partidárias e suas alianças. Orientações ideológicas diversas se uniram sem constrangimento. Essa falta de consistência, para o autor, “confirma a irrelevância da política partidária no capitalismo contemporâneo. Irrelevância que é mais grave na periferia do que no centro. Os partidos representam pouco, e a política está centrada sobretudo nas personalidades" (ibid., p.22). 
A formulação da ideia de uma "hegemonia às avessas" decorre do que Oliveira coloca como uma "provocação gramsciana", que seria típica da era da globalização. O país precursor desta nova forma de dominação teria sido a África do Sul. Em resumo, essa ideia pode ser formulada da seguinte maneira: "enquanto as classes dominadas tomam a 'direção moral' da sociedade, a dominação burguesa se faz mais descarada" (ibid., p.24). No caso da África do Sul, as classes dominadas derrotaram o apartheid e o governo oriundo dessa derrota se rendeu ao neoliberalismo - "assim, a liquidação do apartheid mantém o mito da capacidade popular para vencer seu temível adversário, enquanto legitima a desenfreada exploração pelo capitalismo mais impiedoso" (ibid., p.24).

O Brasil estaria próximo desse caso. A "era da invenção" - que, como vimos, foi trabalhado por Oliveira em Política numa era da indeterminação e em O momento Lênin - teria não apenas fornecido a "direção moral" da sociedade brasileira em relação à resistência à ditadura, como também teria criado a ideia de que a pobreza e a desigualdade estão no "primeiro plano da política". Neste sentido, o Bolsa Família pode ser comparado à derrota do apartheid, bem como a eleição de Lula pareceu ter desafiado os preconceitos de classe e as barreiras da desigualdade. Assim, a condição de mito à qual Lula é elevado teria como resultado prático a despolitização das questões da pobreza e da desigualdade, de modo que elas passam a figurar como problemas puramente administrativos. Afirma Oliveira: "ele as transforma em problemas de administração, derrota o suposto representante das burguesias - o PSDB, o que é inteiramente falso - e funcionaliza a pobreza. Esta, assim, poderia ser trabalhada no capitalismo contemporâneo como uma questão administrativa" (ibid., p.25).

Além disso, em seu primeiro mandato, Lula teria cooptado os movimentos sociais e as organizações da sociedade civil, o que teria enfraquecido a atuação e a agenda dos movimentos sociais. Em suma: a vitória de Lula teria "anulado" as esquerdas no país, de modo que toda crítica seria "imediatamente identificada como sendo de 'direita". Nesse sentido, haveria um distanciamento entre a esquerda independente, o PT e Lula. Por outro lado, a mídia segue atacando o governo, "o que contribui para confundir a crítica da esquerda com a crítica da própria imprensa". A "hegemonia às avessas" seria um fenômeno novo, e que, portanto, exige novas reflexões:

Não épatrimonialismo, pois o que os administradores dos fundos de pensão gerem é capital-dinheiro. Não é o patriarcalismo brasileiro de Casa-grande e Senzala, de Gilberto Freyre, porque não é nenhum patriarca que exerce o mando nem a economia é "doméstica" (no sentido do domus romano), embora na cultura brasileira o chefe na política possa se confundir, às vezes, com o "pai” - Getúlio 
Vargas foi apelidado de "pai dos pobres" e Lula pensa em tomar-lhe o lugar, mas o que ele gere, com sua classe, é o capital. Não é populismo, como sugere a crítica da direita, e mesmo de alguns setores da esquerda, porque o populismo foi uma forma autoritária de dominação na transição da economia agrária para a urbanoindustrial. E o populismo foi - de forma autoritária, enfatize-se - a inclusão sui generis da nova classe operária, desbalanceando a velha estrutura de poder no Brasil e deslocando fortemente os latifundiários da base de dominação. Nada disso está presente na nova dominação (ibid., p.25-26 - grifo nosso).

Com isso, Oliveira pretendeu indicar a necessidade de se compreender melhor os "regimes políticos que, avalizados por uma intensa participação popular $[\ldots]$ ao chegar ao poder, praticam políticas que são o avesso do mandato das classes recebido nas urnas" (OLIVEIRA, 2010B, p.369). Em O avesso do avesso (2010B), o autor reconhece que o mandato conferido a Lula não carregava expectativas revolucionárias de seu eleitorado, mas carregava expectativas intensamente reformistas de:

[...] avanços na socialização da política em termos gerais e, especificamente, alargamento dos espaços de participação nas decisões da grande massa popular, intensa redistribuição da renda num país obscenamente desigual e, por fim, uma reforma política e da política que desse fim à longa persistência do patrimonialismo (ibid., p.369).

A resultante, contudo, foi contrária à esperada. Ou melhor, foi o seu avesso. A justificativa para isso é o "eterno argumento dos progressistas conservadores", de que é preciso apoio no Congresso para governar e, sem ele, o país seria ingovernável - "daí a necessidade de uma aliança ampla. Ou de uma coalizão acima e à margem de definições ideológicas. Ou, mais simplesmente, de um pragmatismo irrestrito" (ibid., p.370). FHC buscou, com esse argumento, justificar a maior mudança ideológica que se viu no país, que é assolado pela "longa tradição nacional do "transformismo"”.

Oliveira nega que o atraso governe o país, como na tese da "revolução passiva" positivada e defendida por Werneck Vianna. ${ }^{6}$ Ao contrário, para o sociólogo, prevalecem as modernizações, mesmo que com traços conservadores. Ou seja: no amálgama entre "atraso"

\footnotetext{
${ }^{6} \mathrm{Em}$ A revolução passiva: iberismo e americanismo no Brasil, Werneck Vianna lida com a polêmica tarefa que é a discussão em torno das diversas interpretações que os textos gramscianos podem assumir. Sua questão central é a expressão assumida pelo conceito gramsciano de revolução passiva no contexto brasileiro. Embora a discussão seja "especializada", é interessante notar o esforço teórico, também estratégico, de Vianna ao adentrar no pensamento gramsciano enquanto justificativa de sua análise histórica da modernização do Estado brasileiro. Para Vianna, o Brasil, mais do que qualquer outro país da América Ibérica, é o lugar por excelência da revolução passiva, na medida em que chegou a modernização em compromisso com o seu passado. Embora o país desconheça a experiência da revolução, não tratar-se-ia de uma "ideia fora do lugar". Para o autor, num contexto em que "o mundo não mais desejava reconhecer-se nas revoluções", o referencial analítico gramsciano para a interpretação da revolução passiva adquire uma atualidade geral, não dizendo mais respeito a casos singulares nacionais. Desta forma, a análise gramsciana configuraria uma "sociologia política", "raiz de um novo modelo para a atuação da esquerda nos países de grandes 'reservas políticas e organizativas”' (VIANNA, 2004, p.69). Assim, fica claro como o "conceito" utilizado por Gramsci ganha uma nova configuração nas palavras de Vianna - de critério de interpretação passa a ser um "modelo de atuação da esquerda", do plano analítico ao plano propositivo.
} 
e "moderno", prevalece o segundo polo, que funcionaliza o primeiro e não o contrário. Sinal disso foi o impacto da chegada de Fernando Henrique Cardoso ao poder, que resultou num programa que nem mesmo Margaret Thatcher ousou realizar em seu país. Manipulando o fetiche da moeda estável, o presidente vinculado ao PSDB retirou do Estado brasileiro a capacidade de fazer política econômica. Com os dois mandatos, os "tucanos" operaram um tournant do qual seu sucessor veio a ser prisioneiro - com a peculiaridade de que Lula radicalizou o descumprimento de um mandato que lhe foi conferido para reverter o desastre de FHC. É nesse contexto que opera a "hegemonia às avessas" (ibid., p.373).

Por fim, Oliveira compreende o Governo Lula como o "avesso do avesso". Do ponto de vista econômico, sustenta que: 1) a taxa do crescimento médio nos seis anos do governo Lula foi menor que a média histórica da economia brasileira; 2) a previsão feita para 2009 levaria ao mesmo nível da performance do governo FHC; 3) o crescimento se baseou "numa volta à "vocação agrícola" do país. Do ponto de vista social: 1) ao contrário da propalada ideia de redução da desigualdade gerada pelo Bolsa Família, os dados disponíveis não indicam redução da desigualdade, embora deva ser certo que a pobreza absoluta diminuiu. A desigualdade provavelmente aumentou, para o autor, que considera os resultados proclamados como falsos, pois medem apenas as rendas do trabalho que, na verdade, melhoraram muito marginalmente, graças aos benefícios do INSS e não do Bolsa Família (ibid., p.373). Do ponto de vista político, o "avesso do avesso" é sua negação por meio da cooptação de centrais sindicais e movimentos sociais.

Em outro plano, Oliveira sustenta que as classes sociais desapareceram: o operariado formal foi encurralado e retrocedeu, enquanto seus irmãos informais cresceram do outro lado (ibid., p.375). Assim, afirma que o avesso da "hegemonia às avessas" é a "face [...] de alguém que vestiu a roupa às pressas e não percebeu que saiu à rua do avesso". Concluindo, o autor sustenta que o lulismo seria, então, "uma regressão política, a vanguarda do atraso e o atraso da vanguarda".

\section{DO PONTO DE VISTA DOS DE BAIXO: DECEPÇÃO E ESPERANÇA}

Um ponto central do argumento de Singer se refere ao realinhamento eleitoral. Para o autor: 
Teria havido, a partir de 2003, uma orientação que permitiu, contando com a mudança da conjuntura econômica internacional, a adoção de políticas para reduzir a pobreza - com destaque para o combate à miséria - e para a ativação do mercado interno, sem confronto com o capital. Isso teria produzido, em associação com a crise do "mensalão", um realinhamento eleitoral que se cristaliza em 2006, surgindo o lulismo. O aparecimento de uma base lulista, por sua vez, proporcionou ao presidente maior margem de manobra no segundo mandato, possibilitando acelerar a implantação do modelo "diminuição da pobreza com manutenção da ordem” esboçado no primeiro quadriênio (SINGER, 2012, p.13).

Aqui lhe interessa "apenas a ideia de que certas conversões de blocos de eleitores são capazes de determinar uma agenda de longo prazo, da qual nem mesmo a oposição ao governo consegue escapar” (ibid., p.13-4). Essa agenda, no caso do Brasil de Lula, é apoiada pela nova base social - o subproletariado - e teria favorecido a adoção de medidas socioeconômicas que propiciaram tanto o crescimento econômico como a diminuição da desigualdade. Daí o ressurgimento, na dimensão do embate ideológico, da oposição entre "povo" e "antipovo", que também passa a ter um traço marcadamente regional. Ao mesmo tempo, passa a haver uma oposição entre "Norte" e "Sul". Lembrando do argumento de Francisco de Oliveira sobre como a dimensão moderna do país - o Sul - funcionaliza os seus aspectos arcaicos - o Norte - diz o cientista político:

\begin{abstract}
A singularidade das classes no Brasil consiste no peso do subproletariado, cuja origem se deve procurar na escravidão, que ao longo do século XX não consegue incorporar-se à condição proletária, reproduzindo uma massa miserável permanente e regionalmente concentrada. O Norte e o Nordeste têm índices de pobreza maiores que o do Sul e do Sudeste. O populoso Nordeste, em particular, é o principal irradiador de imigrantes paras as regiões mais prósperas. Por isso, entendo que, ao tocar na questão da miséria, dinamizando, sobretudo, a economia nordestina, o lulismo mexe com a nossa “questão setentrional”: o estranho arranjo político que os excluídos sustentavam a exclusão (ibid., p.21).
\end{abstract}

A viravolta aqui é grande: utilizando o argumento clássico formulado por Oliveira em Crítica à rą̧ão dualista (2013B), Singer indica uma dimensão bastante esperançosa do lulismo - ele abriria a possibilidade de modificar o próprio cerne social que faz o capitalismo brasileiro se reproduzir de maneira tão perversa. A análise segue, no entanto, matizando as expectativas. $\mathrm{O}$ autor indica que as mudanças lulistas são pequenas frente às expectativas radicais que os altíssimos graus de desigualdade social no Brasil geram, mas que, por isso mesmo, elas tiveram um impacto grande naqueles excluídos que sustentam - sustentavam? - a exclusão. O mecanismo chave para essa mudança foi o estímulo do mercado interno, que no Brasil é potencialmente grande - dada a enorme população - mas é - era? - fraco, dados os níveis rebaixadíssimos de renda de boa parte dela.

Vale notar que a conjuntura internacional favoreceu a guinada do segundo mandato de Lula, que pôde, devido à exportação de commoditites, aprofundar as políticas de combate à 
miséria. Porém, Singer observa o risco de diminuir o lulismo a um mero fenômeno da conjuntura externa. Se de fato houve um reaquecimento da economia mundial entre o período de 2003 a 2007, o autor indica que mesmo antes deste período virtuoso da economia capitalista, o primeiro governo do PT já fazia a opção da transferência de renda de parte do PIB para os mais pobres aproveitando os cortes de gastos que realizava no âmbito do pessoal e dos investimentos. Com isso o autor destaca a opção e a ação do governo do PT - "foi a fortuna da conjuntura internacional associada à virtù de apostar na redução da pobreza com ativação do mercado interno que produziu o suporte material do lulismo" (ibid., p.179). O segundo mandato, com a economia aquecida, permitiu que os gastos em pessoal e investimentos fossem retomados, gerando a imagem de prosperidade que temos do período. Sem aprofundar a questão, se assinala que foi esse aquecimento prévio do mercado interno com relação à crise de 2008 que pode ter possibilitado a saída pelo consumo.

Com o mesmo sentido de matização, que procura dar conta do caráter contraditório do lulismo, Singer discute o seu tempo. Ou seja, o autor busca discutir a velocidade com a qual o arranjo político lulista enfrenta as contradições brasileiras. A discussão também é ambígua, pois como observa:

\footnotetext{
Desde esse ponto de vista, é correto afirmar que, mesmo tendo havido redução da desigualdade no governo Lula, ela foi insuficiente para tirar o país do quadrante em que estão as nações mais desiguais do mundo. O argumento, no entanto, se aplica menos ao que aconteceu no governo Lula e mais ao que veio antes de Lula (ibid., p.185).
}

De acordo com Singer, a velocidade da queda da desigualdade social no Brasil durante o governo Lula não foi baixa. A sensação de lentidão do lulismo seria fruto do seu "ponto de partida", que seria a desigualdade social abissal vigente no Brasil. É nesta altura que entra a discussão do caráter político do lulismo. Quando da chegada do PT ao governo federal, se esperava a adoção do que Singer chamou de "reformismo forte" - em concordância com Oliveira - que era a perspectiva adotada pelo PT no tempo no qual vigorava o "espírito do Sion", também chamado de "primeira alma" do Partido dos Trabalhadores. O modo de se estabelecer tal reformismo seria a intensa mobilização popular - como destacava Singer em seu livro de 2002. No entanto, a "proposta de auto-organização para a luta política de classes, que estava no âmago dos grupos que formaram o PT na década democrática (1978-1988), não foi assumida pelo governo Lula” (ibid., p.188).

Notemos aqui duas diferenças importantes do lulismo frente ao "reformismo forte": sua velocidade e seu modus operandi. Quanto ao primeiro ponto, Singer busca 
estabelecer as conexões entre as políticas adotadas durante os governos Lula e a plataforma originária do PT, mas indicando que tiveram como princípio o não-confronto com o capital, o que as distancia das propostas fundantes do partido. O friso do autor, no entanto, se dá sobre a questão da continuidade das propostas e não sobre as suas rupturas, o que lhe permite afirmar que o reformismo fraco "não é o avesso do reformismo forte, e sim sua diluição". Sinteticamente:

[...] ao tomar das propostas originais do PT aquilo que não implicava enfrentar o capital como seria o caso da tributação das fortunas, revisão das privatizações, redução da jornada de trabalho, desapropriação de latifúndios ou negociação de preços por meio de fóruns de cadeias produtivas, o lulismo manteve o rumo geral das reformas previstas, não obstante aplicando-as de forma muito lenta. É a sua lentidão que permite interpretá-lo como tendo um sentido conservador (ibid., p.192-193).

É necessário destacar, aqui, outra diferença entre Oliveira e Singer na análise do lulismo, a que se refere à sua dimensão conservadora. Enquanto o sociólogo interpreta o lulismo como conservador pois se submete aos desmandos do capitalismo financeiro internacional, o cientista político indica outro traço que seria característico ao conservadorismo do lulismo: sua lentidão. Aqui, fica claro um elemento de esperança que Singer projeta no arranjo lulista, enquanto Oliveira pouco percebe de positivo nele.

Quanto ao destacado modus operandi, o autor indica o distanciamento que o lulismo impôs entre o PT e os movimentos sociais. Assim, se este arranjo político permite a ascensão do subproletariado ao proletariado, nem por isso deixa de ter uma face negativa: não combate a desregulamentação do trabalho - o que é coerente com toda a análise, pois o lulismo não combate o capital. Para sermos mais exatos: o lulismo não permite que a precarização avance, mas também não a faz regredir.

Aprofundando a análise do modo como é conduzida a política no arranjo lulista, Singer destaca a tentativa dos governos Lula e Dilma de equilibrarem as classes fundamentais do capitalismo, contando com o apoio do subproletariado. Isso porque a política arbitral do lulismo só pode resistir enquanto nenhum dos dois polos tiver força para impor seu domínio sobre o outro - o que afasta o lulismo, como se percebe, do reformismo forte, que aposta no domínio dos explorados.

Do ângulo "de cima", ganha importância a liderança que logra lidar com as contradições de interesses das classes. Em termos marxistas clássicos, se trata de uma situação típica do bonapartismo - segundo o vocabulário gramsciano, o arranjo lulista comporta algo de cesarismo. Note-se que essa combinação entre desmobilização de classes 
com protagonismo da liderança só é possível no momento em que é possível ceder ao mesmo tempo a diferentes lados da disputa. Essa característica é a que permite ao líder formular discursos variados, sempre dependentes de quem o ouve.

Importa destacar que, não obstante o fato de diversas classes e frações de classes participarem do arranjo lulista, a base de sustentação do arranjo, aquela que detém o "entusiasmo" pelo lulismo, é o subproletariado. O "outro" desta fração de classe é a pequena burguesia, que está fora do arco de alianças sociais que sustentam o lulismo, que vai desde os "super-ricos" até os subproletários. Não à toa é a base de sustentação do PSDB, que o lulismo - paradoxalmente? - fortaleceu. Desta forma, o lulismo conseguiu criar um certo descolamento entre os setores dominantes no Brasil no que se refere aos seus posicionamentos políticos: enquanto o topo da pirâmide não se opõe ao lulismo, a "base" dos dominantes, a pequena burguesia, é o esteio principal da oposição. Sem entrar no mérito da questão, que não deixa de ser interessante, observemos que, segundo Singer, "para a burguesia, o reformismo fraco representa um caminho possível, embora não o de sua predileção, para o desenvolvimento do capitalismo no país, sem que a sua posição esteja ameaçada" (ibid., p.207).

A passagem desperta interesse por vários motivos. Um primeiro ponto a ser esclarecido é a diferença entre os posicionamentos da burguesia e o da pequena-burguesia: a primeira não está com sua posição ameaçada no regime lulista, enquanto a segunda está. Isto é, a ascensão social dos mais pobres os aproxima da classe média tradicional, que vê tal movimento com maus olhos; por outro lado, a distância entre os ascendentes e o topo da pirâmide social ainda é enorme. Outra questão que a passagem citada levanta é sobre o papel da burguesia nacional no desenvolvimento do capitalismo brasileiro. Aqui, Singer dialoga diretamente com a chamada "tradição da formação".

De passagem, lembremos as esperanças que alguns intelectuais e organizações depositaram - como o Instituto Superior de Estudos Brasileiros (ISEB), o Partido Comunista Brasileiro (PCB) e Celso Furtado - no papel da burguesia nacional no desenvolvimento brasileiro no fim dos anos 1950 e início da década seguinte. Em diálogo direto com tais hipóteses, Fernando Henrique Cardoso ([1963]1972) fez uma pesquisa sobre o empresariado industrial do país e concluiu que tais desejos não encontravam chão histórico. Em passagem marcante, afirmou que: 


\begin{abstract}
No capítulo final vimos as inconsistências do projeto de hegemonia política da burguesia industrial [...] Hesita não porque não se dá conta de seus interesses reais, mas porque estes interesses são contraditórios [...] Para assegurar a expansão econômica e tentar o controle político do momento arrisca-se a perder a hegemonia no futuro. Por isso, volta-se imediatamente depois de qualquer passo adiante contra seus próprios interesses, recuando um pouco no presente para não perder tudo no futuro (CARDOSO, 1972, p.197).
\end{abstract}

O acerto do diagnóstico do sociólogo foi comprovado com o golpe de 1964. Daí, aliás, decorreram as discussões sobre o chamado "desenvolvimento dependente associado" (CARDOSO, 1969, 1978; CARDOSO E FALETTO, 1973). Sem desconhecer as mudanças que ocorreram no capitalismo desde os anos 1960 e 1970, o que queremos levantar com tal questão é a similaridade entre os cenários de pré-1964 e o atual, ao menos no que se relaciona às expectativas com a ascensão dos "de baixo" e ao papel que a burguesia nacional poderá ter nessa situação. Segundo o que nos conta o próprio Singer (2015), não é o caso de se ter muitas esperanças.

\title{
4. CONSIDERAÇÕES FINAIS
}

Como indicamos no início do texto, nos interessa uma leitura que destaque a complementaridade das análises de Francisco de Oliveira e André Singer. O ponto central de uma possível convergência entre os autores está na dimensão negativa das possibilidades da política no cenário atual. Seja porque permaneçamos num cenário "indeterminado", no qual o capital tem amplíssima margem de manobra, ou sob um arranjo político que, a despeito das melhorias de condições de vida que propiciou aos mais pobres, não estimula a organização da sociedade civil e das classes trabalhadores. A questão permanece a das possibilidades da democracia brasileira se tornar efetiva, por meio de seu empoderamento e da organização de seus estratos.

É certo que existem diferenças entre as visões dos autores sobre o assunto. Enquanto Oliveira indica um processo de fragilização crescente das forças democráticas, que vão se tornando irrelevantes frente aos desmandos do sistema econômico, Singer parece ter esperança de que, ainda que o lulismo avance muito lentamente, o processo de identificação do subproletariado com uma plataforma política pode inaugurar uma nova reorganização política das forças sociais subalternas. É sabido o papel que o PT assumiu outrora nesse sentido - em vista das alterações que este partido sofreu ao longo das últimas décadas, mudanças que tanto Oliveira quanto Singer parecem concordar, resta pouca esperança que este partido possa responder às questões pontuadas para o presente. Há, ainda, uma segunda 
questão subjacente ao ponto acima analisado: a questão de como o lulismo atual se relaciona frente à configuração sócio-histórica do capitalismo brasileiro. Ele daria conta de enfrentar suas principais contradições? Essa questão encontra cada vez menos espaço no debate contemporâneo.

Para Oliveira, vimos que a resposta à pergunta acima é negativa. O lulismo, aliás, organiza e legitima a exploração, como afirma a tese da "hegemonia às avessas". Por sua vez, para Singer, se trata de um movimento ambíguo, típico de um arranjo político caracterizado como "contraditório" - por um lado, o lulismo pode incidir sobre a nossa "questão setentrional", atingindo um dos pontos centrais da reprodução sistêmica e rebaixada do capitalismo brasileiro. Por outro, sua fraqueza em tomar um lado na disputa política - coisa que não pode fazer sem se descaracterizar - indica que quando necessário para o capital, o retrocesso está à vista. O posicionamento amigável frente aos arranjos dominantes pode ser visto como uma estratégia de mudança, mas pode dar em capitulação política. Sinal dessa tensão aparece na análise que o cientista político faz sobre a burguesia nacional, que remonta a antigas esperanças.

Enfim, nas suas análises sobre os impasses entre democracia e capitalismo no Brasil - pois é disso que se trata efetivamente - não é difícil perceber que ambos entreveem como saída o fortalecimento de uma democracia substantiva no país. Aliás, o que é um traço de pertencimento à tradição intelectual a qual se filiam. O cenário político do lulismo ainda está

em movimento e sua interpretação, portanto, está em disputa. É certo que o "ensaio desenvolvimentista" do primeiro governo Dilma Rousseff enfrenta forte regressão neste momento (cf. SINGER, 2015). A pergunta parece ser: estaremos aquém do lulismo no futuro próximo?

\section{REFERÊNCIAS}

Arantes, O.; Arantes, P. 1997. Sentido da formação. São Paulo: Paz e Terra.

Braga, R. 2010. Apresentação. In: Oliveira, F; Braga, R. (ORGS). Hegemonia às avessas. São Paulo: Boitempo.

CArdoso, F. H. 1969. Mudanças sociais na América Latina. São Paulo: Difusão Europeia do Livro (Difel). 
.1972. Empresário industrial e desenvolvimento econômico no Brasil. São Paulo: Difusão Européia do Livro (Difel).

.; Faletto, E. 1973. Dependência e desenvolvimento na América Latina: ensaio de interpretação sociológica. Rio de Janeiro: Zahar.

1978. Notas sobre o estado atual dos estudos sobre dependência. In: SERRA, J. (org.). América Latina: ensaios de interpretação econômica. Rio de Janeiro: Paz e Terra.

Oliveira, F. 2007A. Um crítico na periferia do capitalismo. In: CEVASCO, M.E.; OHATA, M. (ORGS). Um crítico na periferia do capitalismo: reflexões sobre a obra de Roberto Schwarz. São Paulo: Companhia das Letras.

. 2007B. Política numa era da indeterminação. In: OLIVEIRA, F.; RIZEK, C.S. (ORGS). A Era da Indeterminação. São Paulo: Boitempo.

2007c. O momento Lênin. In: Oliveira, F.; RizeK, C.S (ORGS). A Era da Indeterminação. São Paulo: Boitempo, 2007C.

2010A. Hegemonia às avessas. In: Oliveira, F; Braga, R. (ORGS). Hegemonia às avessas. São Paulo: Boitempo.

2010B. O avesso do avesso. In: Oliveira, F; Braga, R. (Orgs). Hegemonia às avessas. São Paulo: Boitempo.

Paulo: Boitempo,

2013A. O ornitorrinco. In: OliveIRA, F. Crítica à razão dualista o ornitorrinco. São

2013B. Crítica à razão dualista. In: OLIVEIRA, F. Crítica à raz̃ão dualista o ornitorrinco. São Paulo: Boitempo.

SANTOS, L. 2007. Brasil contemporâneo: estado de exceção? In: Oliveira, F.; RizEK, C.S (ORGS). A Era da Indeterminação. São Paulo: Boitempo.

SCHWARZ, R. 1999. Fim de século. In: SCHWARZ, R. Sequências Brasileiras. São Paulo: Companhia das Letras.

2012. Prefácio a Francisco de Oliveira, com perguntas. In: Martinha versus Lucrécia: ensaios e entrevistas. São Paulo: Companhia das Letras.

SINGER, A. 2002. Esquerda e Direita no Eleitorado Brasileiro. São Paulo: Edusp.

2009. Raízes sociais e ideológicas do lulismo. Novos estudos, $\mathrm{n}^{\circ} 85$.

2010. A segunda alma do partido dos trabalhadores. Novos estudos, $\mathrm{n}^{\circ} 88$.

2012. Os sentidos do Lulismo. São Paulo: Companhia das Letras.

2015. Cutucando onças com varas curtas - o ensaio desenvolvimentista no primeiro mandado Dilma Rousseff (2011-2014). Novos estudos, $\mathrm{n}^{\circ} 102$.

ViannA, L. W. 2004. A revolução passiva: iberismo e americanismo no Brasil. Rio de Janeiro: Revan. 